\title{
Oncolytic herpes simplex virus-based strategies: toward a breakthrough in glioblastoma therapy
}

\author{
Jianfang Ning and Hiroaki Wakimoto* \\ Department of Neurosurgery, Brain Tumor Research Center, Massachusetts General Hospital, Harvard Medical School, Boston, MA, USA
}

\section{Edited by:}

Ravindra Veeranna, National

Institutes of Health, USA

\section{Reviewed by:}

Patrick Lee, Dalhousie University, Canada

Takayuki Murata, Nagoya University

School of Medicine, Japan

*Correspondence:

Hiroaki Wakimoto, Brain Tumor

Stem Cell Laboratory, Department of Neurosurgery, Brain Tumor

Research Center, Massachusetts General Hospital, Harvard Medical

School, 185 Cambridge Street,

CPZN-3800 Boston, MA 02114, USA

e-mail: hwakimoto@

mgh.harvard.edu
Oncolytic viruses (OV) are a class of antitumor agents that selectively kill tumor cells while sparing normal cells. Oncolytic herpes simplex virus (oHSV) has been investigated in clinical trials for patients with the malignant brain tumor glioblastoma for more than a decade. These clinical studies have shown the safety of oHSV administration to the human brain, however, therapeutic efficacy of oHSV as a single treatment remains unsatisfactory. Factors that could hamper the anti-glioblastoma efficacy of oHSV include: attenuated potency of oHSV due to deletion or mutation of viral genes involved in virulence, restricting viral replication and spread within the tumor; suboptimal oHSV delivery associated with intratumoral injection; virus infection-induced inflammatory and cellular immune responses which could inhibit oHSV replication and promote its clearance; lack of effective incorporation of oHSV into standard-of-care, and poor knowledge about the ability of oHSV to target glioblastoma stem cells (GSCs). In an attempt to address these issues, recent research efforts have been directed at: (1) design of new engineered viruses to enhance potency, (2) better understanding of the role of the cellular immunity elicited by oHSV infection of tumors, (3) combinatorial strategies with different antitumor agents with a mechanistic rationale, (4) "armed" viruses expressing therapeutic transgenes, (5) use of GSC-derived models in oHSV evaluation, and (6) combinations of these. In this review, we will describe the current status of oHSV clinical trials for glioblastoma, and discuss recent research advances and future directions toward successful oHSV-based therapy of glioblastoma.

Keywords: glioblastoma, oncolytic virus, herpes simplex virus type 1, gene therapy, glioblastoma stem cells, combination therapy, synergy, molecular targeted therapy

\section{INTRODUCTION}

Glioblastoma (GBM) is the most common and aggressive primary brain tumor in adults (Wen and Kesari, 2008). The current standard treatment for GBM consists of surgical resection followed by combination of radiotherapy and chemotherapy with the alkylating agent temozolomide (TMZ). Despite this multimodality approach, tumors inevitably recur for which therapeutic options are limited. Median survival of GBM patients is only 14.6 months (Stupp et al., 2005) and this remarkably poor outcome has not improved substantially over the last three decades. Therapeutic challenges include the invasive and infiltrative nature of GBM growth that makes surgical resection always incomplete, and the resistance of tumor cells to the conventional cytocidal therapies. Molecular targeted agents have not achieved an increase in overall survival (Chinot et al., 2014; Gilbert et al., 2014). Thus, there is an urgent need to develop novel, effective therapies for this devastating malignancy.

Oncolytic viruses (OV) have been drawing a great deal of attention as biological anti-cancer agents, with a distinct mechanism of action from conventional cancer therapeutics. $\mathrm{OV}$ is a replication competent virus, either genetically engineered or naturally occurring, which selectively replicates in tumor cells and causes tumor cell death (Russell et al., 2012).
The production of virus progeny leads to secondary infection and virus spread within the tumor and eventual tumor destruction. This process, however, proceeds while sparing normal cells. Selective replication of $\mathrm{OV}$ in tumor cells can be achieved by taking advantage of aberrations found in cancer cells, which include defective innate anti-viral and apoptotic response to viral infection. Thus, viral genes that are not essential for viral growth but required for viral propagation in normal cells can be mutated or deleted to engender tumor selectivity. Many viruses, including both DNA [e.g., herpes simplex virus (HSV)] and RNA (e.g., poliovirus) viruses, have been studied as potential OV platforms for cancer therapeutics.

For GBM treatment, HSV, adenovirus (Chiocca et al., 2004), poliovirus (Gromeier et al., 2000; Goetz and Gromeier, 2010), Newcastle disease virus (Freeman et al., 2006), reovirus (Forsyth et al., 2008; Kicielinski et al., 2014), parvovirus (Herrero et al., 2004), and measles virus (Allen et al., 2013) are at different stages of clinical OV development after preclinical investigations showing anti-GBM activities (Wollmann et al., 2012; Murphy and Rabkin, 2013). Oncolytic HSV (oHSV) is considered particularly suited and promising for treating GBM. A double stranded DNA virus containing $\sim 80$ viral genes, HSV type 1 is a human 
pathogen causing illnesses such as encephalitis, therefore use of HSV as a cancer therapeutic requires genetic engineering. Historically, oHSV has undergone several generations of genetic manipulation during its development as an antitumor agent. The first engineered HSV capable of selective replication and killing GBM was reported by Martuza et al. (1991), which opened the door to applying "virotherapy" for GBM. This seminal work featured an engineered oHSV mutant, dlsptk, which lacks the viral gene encoding thymidine kinase (Gordon et al., 1983; Martuza et al., 1991). Neuropathogenicity issues, however, remained with these HSV-TK mutants. The second gene used to reduce neurovirulence and confer tumor specificity was $\gamma 34.5$, and the deletion of the both copies of $\gamma 34.5$ has been commonly employed to create oHSVs. The gene product of $\gamma 34.5$, ICP34.5, recruits protein phosphatase 1 (PP1) to dephosphorylate eIF2 $\alpha$ leading to inhibition of the protein synthesis shut-off caused by phosphorylated eIF2 $\alpha$ (p-eIF2 $\alpha$ ), a crucial anti-viral defense mechanism mediated by host RNA-induced protein kinase R (PKR) (He et al., 1997). ICP34.5 also binds to the mammalian autophagy protein Beclin 1 to antagonize host autophagy responses (Orvedahl et al., 2007), and forms a complex with proliferating cell nuclear antigen (PCNA), a protein involved in DNA replication and repair (Brown et al., 1997). HSV mutants lacking ICP34.5 maintain the capability of replication in tumor cells where ICP34.5 is not required for production of infectious progeny, whereas they fail to replicate in normal neurons where ICP34.5 is essential for viral replication (MacLean et al., 1991; McKie et al., 1996, 1998). The third viral gene used to attenuate oHSV is UL39, which encodes the large subunit of ribonucleotide reductase (ICP6) (Goldstein and Weller, 1988; Mineta et al., 1994). ICP6 is required for efficient viral growth in non-dividing cells but not in many dividing cells with abundant dNTP pools or in cells with mutated p16 (Aghi et al., 2008). The second generation of oHSV was developed based upon the first generation mutants and contains multiple gene mutations/deletions. G207 has deletions at both $\gamma 34.5$ loci and a lac $Z$ gene insertion inactivating the ICP6 gene (UL39) (Mineta et al., 1995). Some newer oHSVs with additional properties have been developed based on the mutants indicated here and include so-called "armed" oHSV carrying therapeutic transgenes.

oHSV has been shown to be effective for the treatment of a variety of cancer types as reviewed in (Shen and Nemunaitis, 2006; Liu et al., 2013a), and an oHSV expressing GM-CSF has demonstrated clinical efficacy in malignant melanoma trials (Senzer et al., 2009).

Progress in improving oHSV therapy for GBM has been steady but slow; it is over 20 years since the discovery of the oncolytic potential of oHSV for GBM therapy, and clinical exploratory investigations of oHSV began more than a decade ago. Preclinical and clinical research of oHSV has not only shown great potential for GBM treatment, but also revealed drawbacks and limitations of the exiting oHSV strategies and the need for further refinement. In this article, we will summarize the current status of oHSV in GBM clinical trials, discuss recently described oHSV strategies, and propose future directions for successful oHSV application to clinical GBM therapy.

\section{OHSV CLINICAL TRIALS FOR GBM}

HSV1716 is one of the first generation engineered oHSVs, with deletions in both copies of the neurovirulence gene $\gamma 34.5$ for selective replication in tumor cells. A series of 3 phase I clinical trials using HSV1716 were conducted in the UK and reported on from 2000 to 2004 (Rampling et al., 2000; Papanastassiou et al., 2002; Harrow et al., 2004). The first study evaluated the safety of intratumoral injection of HSV1716 in 9 patients with recurrent malignant glioma (Rampling et al., 2000). HSV1716 at doses of $10^{3}-10^{5}$ pfu (plaque forming unit) did not induce adverse clinical symptoms or reactivation of latent HSV, demonstrating the safety and feasibility of intratumoral administration of HSV1716. In the second study, 12 patients with malignant glioma (including 11 GBM) received an intratumoral injection of $10^{5}$ pfu HSV1716, and 4-9 days after inoculation, tumors were removed and assayed for viral replication (Papanastassiou et al., 2002). HSV1716, in excess of the input dose, was recovered from the injection site in 2 patients. PCR detected HSV DNA at the sites of inoculation in 10 patients and at distal tumor sites in 4; HSV-specific antigen was detected in 2 tumors. Five patients, including 2 sero-negative cases, showed increases in levels of HSV-specific IgG and IgM, indicating an immunological response to HSV1716. This study for the first time demonstrated that oHSV replicates in malignant gliomas without causing toxicity in both HSV-seropositive and -seronegative patients. The third trial assessed the safety of HSV1716 injection into the brain adjacent to tumor and the ability of the virus to eliminate any residual tumor (Harrow et al., 2004). Twelve patients with recurrent or newly diagnosed highgrade gliomas underwent tumor resection, and received a total of $10^{5}$ pfu HSV1716 injected into 8 to 10 sites around the resulting tumor cavity. There was no clinical evidence of toxicity associated with virus administration. Three patients remained alive and clinically stable at 15-22 months post-surgery and HSV1716 injection, including 1 patient in which magnetic resonance imaging (MRI) demonstrated a reduction of tumor volume over 22 months. This study showed the safety of HSV1716 injection into the brain adjacent to excised tumor, and potential efficacy of HSV1716 in glioma patients.

Results of clinical trials using G207 conducted in the US were published in 2000, 2009, and 2014 (Markert et al., 2000, $2009,2014)$. A phase 1 trial designed to determine the safety of G207 inoculation into gliomas recruited 21 patients with recurrent malignant gliomas (16 GBMs and 5 anaplastic astrocytomas), and used escalating vector dose from $1 \times 10^{6}$ to $3 \times 10^{9}$ pfu (Markert et al., 2000). No serious toxicity attributable to G207 was observed. There were radiographic (MRI) and neurological findings suggestive of anti-tumor activity. In 4 patients who underwent tumor re-resection after G207 inoculation, PCR detected G207 DNA in tumors from 2 patients, whose resections were done 56 and 157 days after inoculation. One GBM patient who showed tumor regression in post-treatment MRI passed away due to a stroke 10 months after G207 treatment and autopsy showed no evidence of GBM.

The following phase 1b study used two inoculations of G207 before and after tumor resection in six patients with recurrent GBM (Markert et al., 2009). First virus inoculation $\left(1.5 \times 10^{8}\right.$ $\mathrm{pfu}$ ) was given intratumorally via a catheter, and 2-5 days later 
second virus $\left(1 \times 10^{9} \mathrm{pfu}\right)$ was injected into the brain surrounding the resection cavity immediately following resection. One patient experienced transient hyperthermia and decreased responsiveness, which was probably related to G207 administration into the ventricles. The small sample size rendered efficacy assessment difficult, but there was no radiographic complete or partial response and median survival after G207 administration was 6.6 (2-20.75) months. Viral replication was detected in 3 patients by RT-PCR and in 5 patients by immunohistochemistry for the late protein gC. However, infectious G207 was isolated from the tumor of only one patient. No shedding of G207 was detected from serum, conjunctive and saliva. Increases in mononuclear CD3, CD8 and HAM56+ immune cell infiltrates were noted in post-G207 tissue in the majority of patients. This study demonstrated the viral replication of G207, and possible antitumor activity and an overall good safety profile of multiple dose delivery of G207, including direct inoculation into the brain adjacent to tumor resection cavities.

Very recently, the results of a phase 1 trial combining G207 with radiation therapy (NCT00157703) were reported (Markert et al., 2014). Nine recurrent glioma patients (7 GBMs) received stereotactic intratumoral inoculations of G207 at $10^{9} \mathrm{pfu}$, and $24 \mathrm{~h}$ later were treated with single focal irradiation (5 Gy). Treatment was well tolerated. Three patients showed marked radiographic responses, and the median survival time from G207 injection until death was 7.5 months. This study showed the safety and the potential for clinical response of the combinatorial treatment of G207 and radiation for malignant glioma.

In these clinical trials, the maximum tolerated dose (MTD) was never reached and the use of these mutant HSVs in human brain was generally well tolerated. No patient has ever developed HSV encephalitis. While efficacy evaluation was not a primary objective of these studies, instances of tumor regression by MRI or autopsy, and of long-term survival as long as 22 months after HSV1716 injection are encouraging signs (Harrow et al., 2004). Tumor resection after viral inoculation provided evidence for replication of HSV1716 (Papanastassiou et al., 2002) and G207 (Markert et al., 2009), but at relatively low frequency with 2 of 12 patients (Papanastassiou et al., 2002) and 3 of 6 patients (Markert et al., 2009), respectively. This low rate of replication detection may indicate ineffective replication and spread of oHSV, which could directly compromise its efficacy in GBM therapy. These clinical studies also showed that oHSV injection in the human brain induces immune responses, including sero-conversion and recruitment of immune cells to the site of oHSV infection (Papanastassiou et al., 2002; Harrow et al., 2004; Markert et al., 2009). Mononuclear immune cells such as macrophages and T lymphocytes could play major and different roles in modulating oHSV efficacy by prematurely clearing oHSV as innate and adaptive immune response or by attacking tumor cells as anti-tumor effectors. In this regard, the information available from these published studies is preliminary and limited, and future investigations should decipher the complex interaction of the host immune system and oHSV infection of GBM. Thus, these clinical trials, although exhibiting promise, revealed challenges and unanswered questions.
In addition to these published trials, ongoing or unpublished clinical studies testing newer oHSVs for malignant gliomas are listed in Table 1. G47 $\Delta$ is a third generation oHSV created from G207 with an additional deletion within the nonessential $\alpha 47$ gene. The absence of $\alpha 47$ leads to increased MHC class I expression, and early expression of Us 11 driven by the immediate-early $\alpha 47$ promoter enhances the growth of $\gamma 34.5$ mutants (Todo et al., 2001). rQNestin34.5, a HSV mutant in which one copy of the $\gamma 34.5$ gene was reinserted into the UL39-deleted, $\gamma 34.5$-deleted viral genome under control of the nestin promoter, exhibits increased replication in GBM cells (Kambara et al., 2005). M032 has a similar construction as M002, lacking both copies of the $\gamma 34.5$ gene and expressing human IL-12 (Roth et al., 2014). All of these have shown promising safety or antitumor efficacy in preclinical GBM studies, and are currently in active clinical trials or in preparation for trials.

\section{CURRENT STRATEGIES USING OHSV FOR GBM THERAPY}

Since clinical trials have shown apparently limited efficacy of oHSV for GBM, how to improve efficacy while retaining safety has become the focus of preclinical and clinical oHSV research. To this end, recent research efforts have been directed at different areas that include: (1) use of GBM cancer stem cell-derived models in oHSV evaluation, (2) design of new engineered viruses to enhance potency, (3) better understanding of the role of the cellular immunity elicited by oHSV infection of tumors, (4) combinatorial strategies with different antitumor agents with a mechanistic rationale, and (5) "armed" viruses expressing therapeutic transgenes. In this section, we will overview recent relevant publications and summarize cutting-edge strategies and advances toward improving oHSV therapy of GBM.

\section{USE OF GBM STEM CELL-DERIVED MODEL IN OHSV EVALUATION}

With increasing knowledge of GBM biology, the propagation of GBM is thought to be sustained and driven by a subpopulation of neoplastic cells. These cells, termed GBM stem cells (GSCs), exhibit stem cell-like properties of self-renewal and multi-potential differentiation, and efficiently generate tumors upon implantation to immunocompromised mice (Nduom et al., 2012). GSCs appear to play a key role in tumor invasion, resistance to various treatments, and recurrence (Eyler and Rich, 2008) and thus are considered a critical therapeutic target.

We investigated the efficacy of oHSV with different genetic mutations against GSCs isolated from surgical specimens of human GBMs (Wakimoto et al., 2009). Although UL39 (ICP6) mutant $\mathrm{F} \Delta 6$ was as efficacious as wild type strain F, $\gamma 34.5$-deleted oHSV such as R3616 and G207 were unable to replicate in GSCs, exhibiting an attenuated phenotype. However, additional deletion of $\alpha 47$ reversed this phenotype, as G47 $\Delta$ was able to replicate, spread, and kill both CD133+ and CD133-cells, as well as repress secondary sphere formation of GSCs. Thus, potency of oHSV against human GSCs correlated with oHSV mutations. We also showed that a single intratumoral inoculation of G47 $\Delta$ prolonged survival of immunocompromised mice harboring highly invasive GSC-derived intracranial GBM. Friedman et al also showed that both CD133+ and CD133- GBM cells are targetable by oHSV, and that expression of CD111 (nectin-1), an HSV entry receptor, 
Table 1 | Oncolytic herpes simplex viruses in completed and ongoing clinical trials for malignant glioma.

\begin{tabular}{lllllll}
\hline Virus (stain) & Country & Year $^{*}$ & Status & Phase & Protocol & Result \\
\hline 1716 & UK & 1996 & Closed & I & $\begin{array}{l}\text { Intatumoral, } 10^{3}-10^{5} \text { pfu, } \\
\text { single injection }\end{array}$ & $\begin{array}{l}\text { Of } 9 \text { patients treated, } 4 \text { were alive } \\
\text { and well 14-24 months after 1716 } \\
\text { administration. No toxicity or }\end{array}$ \\
& & & & & & serious adverse events.
\end{tabular}

\begin{tabular}{|c|c|c|c|c|c|c|c|}
\hline 1716 & UK & 2000 & Closed & I & $\begin{array}{l}\text { Intatumoral, } 10^{5} \mathrm{pfu} \text {, single } \\
\text { injection }\end{array}$ & $\begin{array}{l}\text { No toxicity or serious adverse } \\
\text { events }\end{array}$ & $\begin{array}{l}\text { (Papanastassiou et al., } \\
\text { 2002) }\end{array}$ \\
\hline 1716 & UK & 2001 & Closed & । & $\begin{array}{l}\text { Adjacent brain, } 10^{5} \text { pfu, } \\
\text { single injection }\end{array}$ & $\begin{array}{l}3 \text { out of } 12 \text { patients remained } \\
\text { alive and clinically stable at } 15-22 \\
\text { months post-surgery and } 1716 \text {. } \\
\text { No toxicity or serious adverse } \\
\text { events. }\end{array}$ & (Harrow et al., 2004) \\
\hline
\end{tabular}

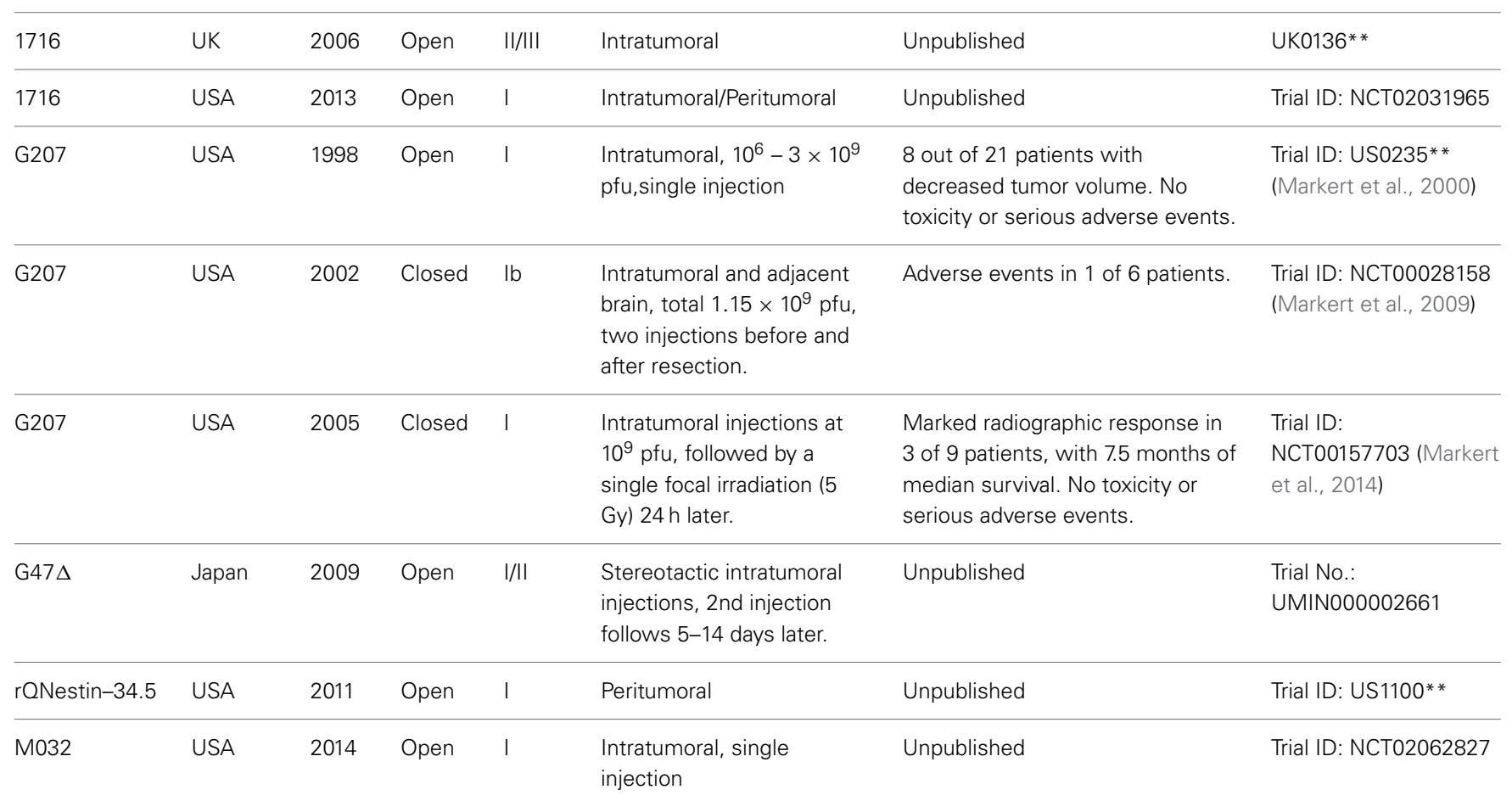

${ }^{*}$ Year approved or initiated.

${ }^{* *}$ According to The Journal of Gene Medicine Clinical Trial site (http://www.abedia.com/wiley/index.html).

is an important factor determining sensitivity to oHSV (Friedman et al., 2009).

GBM contains abundant hypoxic regions that promote the GSC-like phenotype and confer resistance to chemo- and radiotherapy (Li et al., 2009; Seidel et al., 2010). Hypoxia was shown to enhance replication of oHSV G207 in U87 GBM xenografts in vitro and in vivo (Aghi et al., 2009). Sgubin et al. examined the therapeutic effects of G47 $\Delta$ in patient-derived GSCs under normoxia and hypoxia (Sgubin et al., 2012). G47 $\Delta$ infection of GSCs was able to counteract hypoxia-mediated enhancement of the stem-like properties of GSCs, inhibiting their self-renewal and stem cell marker CD133 expression. In orthotopic human GSC xenografts, inoculation of a G47 $\Delta$ derivative, G47 $\Delta$ Us11fluc, demonstrated an equivalent frequency of viral infection and replication in hypoxic and nonhypoxic tumor areas, highlighting the ability of oHSV G47 $\Delta$ to target GSCs in a hypoxic niche environment (Sgubin et al., 2012). On the other hand, $\gamma 34.5$ deleted oHSV C101 was shown to exhibit reduced replication and/or cytotoxicity against GSC-like human xenograft lines under hypoxic as opposed to normoxic conditions despite increased CD111 (nectin-1) expression mediated by hypoxia (Friedman et al., 2012).

Unlike human GBM xenografts, syngeneic GBM models in immunocompetent mice allow critical evaluation of how oHSVinduced adaptive immune responses impact on oHSV therapy of GBM. Murine 005 GBM cells, possessing heterozygous $T p 53$ and activated Ras and Akt, exhibit stem-like properties, including high-level expression of mProminin-1 (CD133 equivalent), and demonstrate histopathological hallmarks of GBM such as cellular heterogeneity, invasion and hypervascularity (Marumoto 
et al., 2009). This syngeneic GSC model enabled detailed characterization of the multifaceted efficacy of G47 $\Delta$-mIL12, including assessment of direct oncolysis, regulatory $\mathrm{T}$ cell downregulation, and anti-angiogenesis (Cheema et al., 2013).

\section{DESIGN OF NEW ENGINEERED VIRUSES TO ENHANCE POTENCY}

Although oHSVs that lack $\gamma 34.5$ are capable of replication in tumor cells, the clinical trials testing HSV1716 and G207 suggested that these $\gamma 34.5$-null attenuated oHSVs may not be potent enough to provide substantial efficacy for GBM. Preclinical research has continued to seek new designs of oHSV that could achieve both potency and safety. Such approaches include deletion of viral genes with partially or fully intact $\gamma 34.5$ and receptormediated tumor specific targeting.

\section{The use of viral gene deletion}

Us3 encodes a serine-threonine kinase that inhibits virus-induced apoptosis and Akt activation. As apoptotic pathways are frequently dysfunctional in tumor cells, oHSV with a Us3 deletion replicates preferentially in tumor cells, but induces apoptosis in normal cells, preventing further replication (Liu et al., 2007). However, Us3 mutant R7041 is not safe enough for intracerebral inoculation. A novel oHSV, MG18L, was constructed that contains a US3 deletion and an inactivating LacZ insertion in UL39 (Kanai et al., 2011). MG18L was severely neuroattenuated in mice, replicates well, and activates Akt in human GSCs. In vivo, intratumoral injection of MG18L had anti-GBM activity in an orthotopic GSC xenograft model (Kanai et al., 2011). Importantly, MG18L like its parental Us3 mutant R7041 was synergistic with inhibitors of phosphatidylinositol 3-kinase (PI3K) in killing tumor cells, and this will be discussed later.

The $\gamma 34.5$ gene of HSV plays a central role in neuropathogenicity and is deleted for tumor selectivity in thus far all oHSVs clinically evaluated for treating malignant gliomas (HSV1716 and G207). Unfortunately, deletion of $\gamma 34.5$ attenuates virus replication even in cancer cells, especially human GSCs (Wakimoto et al., 2009). $\gamma 34.5$-encoded ICP34.5 is a multifaceted protein, and one of its diverse functions is to interfere with autophagy by binding to a cellular protein, Beclin 1 (Atg6) (Orvedahl et al., 2007). Kanai et al. developed a new oHSV, $\Delta 68 \mathrm{H}-6$, with deletion of the $\gamma 34.5$ Beclin 1 binding domain (BBD, aa 68-87), rather than the whole $\gamma 34.5$, in addition to UL39 (ICP6) inactivation (Kanai et al., 2012b). $\Delta 68 \mathrm{H}-6$ exhibited minimal neuropathogenicity in HSV-susceptible mice as opposed to single mutants for BBD $(\Delta 68 \mathrm{H})$ and UL39 $(\Delta 68 \mathrm{HR}-6)$ (Kanai et al., 2012b). $\Delta 68 \mathrm{H}-6$ replicated well in human glioma cell lines and GSCs, effectively killing these cells in vitro and prolonging survival of athymic mice bearing orthotopic human U87 and GSC-derived tumors (Kanai et al., 2012b). In contrast, $\gamma 34.5$ deleted 1716 and 1716-6 barely replicated in GSCs. As expected, infection of $\Delta 68 \mathrm{H}-6$ or 1716-6 induced autophagy in glioma cells, but inhibition of autophagy had no effect on virus replication or p-eIF2 $\alpha$ levels (Kanai et al., 2012b).

\section{Receptor mediated targeting of tumor cells}

EGFR gene amplification is found in $40 \%$ of GBMs and is associated with overexpression of epidermal growth factor receptor
(EGFR) and its truncated mutant form, EGFRvIII (Sugawa et al., 1990; Ekstrand et al., 1992). EGFRvIII presents a tumor specific epitope on the cell surface and can be specifically recognized by a single chain antibody, MR1-1. An oHSV was engineered by fusing MR1-1 to the viral glycoprotein $\mathrm{gC}$, an envelope protein involved in initial virus binding to heparin sulfate on the cell surface (Grandi et al., 2010). This mutant oHSV had 5-fold increased infectivity for EGFRvIII-bearing U87 glioma cells compared to mutant receptor-deficient cells. In vivo, the MR1-1-modified-gC oHSV imparted sustained infection of EGFRvIII ${ }^{+}$U87 glioma subcutaneous xenografts (Grandi et al., 2010). Using a similar strategy, another EGFR-retargeted oHSV was created by introducing a scFv antibody for human EGFR into a mutant form of viral glycoprotein gD (Uchida et al., 2013). The retargeted oHSV, after having another entry accelerating mutation in $\mathrm{gB}$, efficiently and exclusively entered cells that express EGFR. This oHSV, KNE, demonstrated safety upon intracerebral inoculation in mice and increased survival in an orthotopic mouse model of human GBM with up to $73 \%$ of animals showing complete response (Uchida et al., 2013).

R-LM113 is a recombinant HSV created by inserting a $s c F v$ antibody against HER2, human epidermal growth factor 2, into the gD gene (Menotti et al., 2008). R-LM113 is fully retargeted to HER2 since this recombinant HSV lost the ability to enter cells through the natural gD receptors, HVEM and nectin-1, but could selectively infect HER2-expressing cells. In vivo, R-LM113 was safe upon inoculation to the brains of HSV-permissive mice, and was efficacious against PDGF-induced malignant glioma as the treatment improved survival of brain tumor-bearing NOD/SCID and immunocompetent BALB/c mice (Gambini et al., 2012; Reisoli et al., 2012). Thus, tropism manipulation through retargeting fully replication competent HSV to GBM-associated receptors might provide an avenue for increased infectivity and specificity for the target cell as well as efficacy, without compromising safety.

\section{Understanding virus and host interaction}

Elucidation of tumor host responses to HSV and oncogenic pathways that modulate virus replication could lead to the discovery of oHSV efficacy biomarkers and design of novel oHSVs. Recently, activated STAT3 signaling, which represents a central hub in malignant glioma progression and maintenance, was shown to enhance rQNestin34.5 replication (Okemoto et al., 2013b). This is likely due to STAT3 inhibition of type 1 interferon responses in infected glioma cells (Okemoto et al., 2013b). Thus, GBM with elevated STAT3 may represent a preferable target for oHSV therapy.

\section{BETTER UNDERSTANDING OF THE ROLE OF THE CELLULAR IMMUNITY ELICITED BY OHSV INFECTION OF TUMORS}

Host immune responses to oHSV have been shown to be a barrier to efficient viral replication and spread within tumor after initial infection, which could compromise oHSV therapy for GBM (Ikeda et al., 1999; Wakimoto et al., 2004; Fulci et al., 2007). However, the role of different immune cell types and molecular mechanisms regulating oHSV infection has not been fully elucidated. Alvarez-Breckenridge et al. showed that oHSV infection 
induced rapid recruitment and activation of natural killer (NK) cells, which led to premature viral clearance and hindrance to oHSV anti-tumor efficacy in both athymic and immunocompetent mouse models (Alvarez-Breckenridge et al., 2012b). Human NK cells preferentially killed oHSV-infected GBM cells through the interaction between natural cytotoxicity receptors (NCR) NKp30 and NKp46 on NK cells and their ligands on infected GBM cells (Alvarez-Breckenridge et al., 2012b). oHSV titers and efficacy were increased in GBM in $\mathrm{Ncr}^{-/-}$mice. Therefore, oHSV therapy of GBM is partly limited by an antiviral NK cell response involving specific NCRs, uncovering novel potential targets to enhance oHSV cancer therapy. The same group led by Dr. Chiocca further demonstrated that NK cell action against oHSV-infected GBM cells was lessened by the histone deacetylase inhibitor valproic acid through inhibition of STAT5/T-BET signaling and generation of $\gamma$-interferon (Alvarez-Breckenridge et al., 2012a). Given that valproic acid is being used in the clinic as an anti-convulsant, this observation is significant in opening up an opportunity for pharmacological modification of the innate immune response to oHSV to enhance virus replication and efficacy in humans.

The cellular immune response to oHSV is a complex phenomenon involving innate immunity to oHSV that is likely deleterious to efficacy and the subsequent adaptive anti-tumor response that is beneficial. Indeed oHSV infection of tumors acts as an in situ vaccination to elicit tumor specific $\mathrm{T}$ lymphocytes effector responses (Toda et al., 1999). Such an approach to inducing anti-tumor immunity by oHSV can be further boosted by taking advantage of oHSV as a gene delivery vector and expressing immune enhancing factors. Two recent publications described new armed oHSVs expressing murine fms-like tyrosine kinase 3 ligand (Flt3L) and IL12 (Barnard et al., 2012; Cheema et al., 2013), and showed their efficacy to be superior to control oHSV in syngeneic mouse GBM models, underscoring the utility of the immune activating strategy. These strategies will be discussed later in the "armed oHSV" section.

\section{COMBINATIONAL STRATEGIES WITH DIFFERENT ANTITUMOR AGENTS WITH A MECHANISTIC RATIONALE}

The history of cancer therapy development has demonstrated that combinations of multiple anti-cancer modalities are often more efficacious than each single treatment for refractory cancer. Successful targeting of GBM, with its heterogeneity, invasiveness, and multiple oncogenic pathways, likely requires such multimodal approaches. Recent research has uncovered promising combinatorial approaches employing oHSV and other agents that are mechanism-based and often exhibit synergistic anti-cancer effects (Kanai and Rabkin, 2013).

\section{Combination with conventional therapy}

How to incorporate oHSV into the existing standard of care for GBM is a practical and important issue from the perspective of oHSV translation to the clinic. Currently used radiation and TMZ chemotherapy are both genotoxic, while HSV infection also elicits cellular DNA damage responses to facilitate viral replication (Taylor and Knipe, 2004; Lilley et al., 2005; Chaurushiya and Weitzman, 2009). This implies that DNA damage inducers currently used for GBM and oHSV can modulate common DNA repair signaling and provide synergistic impact on cell death.

Previously, TMZ-induced tumor-protective DNA repair pathways, involving cellular GADD34 and ribonucleotide reductase, were shown to enhance oHSV G207-mediated oncolysis in glioma cells (Aghi et al., 2006). Subsequently, Kanai et al reported that G47 $\Delta$ acts synergistically with TMZ in killing human GSCs through oHSV-mediated manipulation of DNA damage responses (Kanai et al., 2012a). Mechanistically, activated ataxia telangiectasia mutated (ATM) was found to be a crucial mediator of synergy. Upon G47 $\Delta$ infection, activated ATM relocalized to HSV DNA replication compartments where it likely enhanced oHSV replication but could not participate in repairing TMZ-induced DNA damage, resulting in extensive DNA damage and cell death. For TMZ-resistant GBM cells expressing O6methylbenzylguanine DNA methyltransferase (MGMT), G47 $\Delta$ and TMZ were still synergistic in the presence of an MGMT antagonist (Kanai et al., 2012a). Combined G47 $\Delta$ and TMZ treatment induced robust DNA damage and markedly extended survival of mice bearing MGMT-negative GSC-derived intracranial tumors at TMZ doses attainable in patients. Triple combination therapy with MGMT antagonist was effective against MGMT-positive orthotopic xenografts (Kanai et al., 2012a).

G47 $\Delta$ was also combined with etoposide, a topoisomerase 2 inhibitor, and the combination showed moderate synergy in killing human GSCs and GBM cell lines (Cheema et al., 2011). This combination did not enhance virus replication, but significantly increased caspase-mediated apoptosis. In vivo, the combined treatment of a single cycle of low-dose etoposide with intratumoral G47 $\Delta$ injection significantly extended survival of athymic mice bearing intracranial human GSC-derived tumors over each single treatment (Cheema et al., 2011).

The combination of OV with ionizing radiation (IR) has been shown to increase therapeutic efficacy through viral interference with DNA repair following irradiation of glioma cells (Hadjipanayis and DeLuca, 2005) and enhanced viral replication by IR (Advani et al., 2006). When combined with IR, $\gamma 34.5$ mutant oHSV resulted in increased viral replication and antitumor effects in murine glioma models (Advani et al., 1998). Advani et al. used $\gamma 34.5$-deleted HSV-1 carrying a late promoter driven luciferase in U87 glioma xenografts and administered IR before or after viral injection to determine optimal temporal sequencing (Advani et al., 2011). Delivering radiation 6-9 h after oHSV injection, i.e., coinciding with the onset of late viral gene expression, resulted in the greatest luciferase expression, infectious virus production, and tumor-xenograft regression (Advani et al., 2011). Therefore, when combined with oHSV, IR administration at an optimal time during the HSV replicative cycle may maximize the combination effect.

\section{Combination with molecularly targeted agents}

Molecular analysis of GBMs has shown that genetic alterations in the PI3K/Akt pathway occur in about $80 \%$ of tumors (Parsons et al., 2008). These molecular changes confer GBMs with proliferative and survival advantages and thus offer an important target for GBM therapy. oHSV MG18L has a deletion of $U_{S} 3$ 
which results in Akt activation (phosphorylation) in infected GBM cells. Combination of MG18L and PI3K or Akt inhibitors (e.g., LY294002, GDC-0941 and Triciribine) was synergistic in killing GSCs and glioma cell lines, but not human astrocytes, through enhanced induction of apoptosis (Kanai et al., 2011). In vivo, the combination significantly prolonged survival of mice bearing orthotopic GBM xenografts, as compared to either agent alone, through enhanced induction of apoptosis (Kanai et al., 2011). This is a good example of a mechanism-based combination strategy that exploits oHSV-mediated alteration of an oncogenic signaling pathway in tumor cells.

\section{Combination with anti-angiogenic agents}

One of the pathological hallmarks of GBM is marked neovascularity, which is considered to promote GBM progression (Das and Marsden, 2013). As an adjuvant strategy to treat GBM, antiangiogenic therapy has been extensively investigated in preclinical and clinical studies (Gerstner and Batchelor, 2012).

An angiostatic peptide, cyclic Arg-Gly-Asp (cRGD, cilengitide), binds to and blocks integrins (Brooks et al., 1994; Friedlander et al., 1995) that are highly expressed on tumorassociated endothelial cells. Cilengitide pretreatment of immunocompetent rats bearing orthotopic GBM enhanced treatment with the UL39 mutant oHSV hrR3 (Kurozumi et al., 2007). hrR3 titer was elevated with the cilengitide pretreatment through the reduction of tumor vascular permeability, immune cell infiltration, and $\gamma$-interferon production. These observations were consistent with the finding that suppression of macrophage infiltration into brain tumors enhances oHSV amplification and spread (Fulci et al., 2007). Cilengitide was also used with a $\gamma 34.5$-deleted, UL39-disrupted oHSV, rHSVQ, modified to express vasculostatin (Vstat120), the fragment of brain-specific angiogenesis inhibitor1 (BAI1), to treat GBM (Fujii et al., 2013). In vitro, treatment with the armed oHSV, named RAMBO (Hardcastle et al., 2010), plus cilengitide enhanced the inhibition of endothelial tube formation and mediated synergistic cytotoxicity on glioma cells. In vivo, combination therapy significantly increased the survival of GBM-bearing athymic mice compared with RAMBO or cilengitide monotherapy (Fujii et al., 2013). Thus, cilengitide enhanced vasculostatin-expressing virus therapy for malignant glioma.

Zhang et al demonstrated another successful example of combining two agents with anti-angiogenic properties (Zhang et al., 2012). In athymic mice bearing intracerebral U87 GBM, systemic administration of Bevacizumab, a monoclonal antibody directed at VEGF, increased spread of G47 $\Delta$-mAngio, G47 $\Delta$ oHSV engineered to secrete anti-angiogenic protein murine angiostatin, as well as the anti-angiogenic effect. Multimodal therapy using Bevacizumab plus G47 $\Delta$-mAngio increased animal survival over each monotherapy alone, which was associated with reduction of collagen and matrix metalloproteinases (MMP) 2 and 9 in tumors (Zhang et al., 2012).

\section{Others}

rQNestin34.5 is a genetically modified version of oHSV rHSVQ with a nestin promoter/enhancer driving expression of a single copy of $\gamma 34.5$, rendering an increased ability to replicate (Kambara et al., 2005). However, this promoter becomes extensively methylated in infected glioma cells, reducing ICP34.5 expression and oncolytic potency. Okemoto al. used demethylating drugs to determine if they improve the efficacy of rQNestin34.5 therapy in malignant glioma models (Okemoto et al., 2013a). 5-Aza improved rQNestin34.5 replication and tumor cell lysis in vitro. In vivo, intratumoral injection of rQNestin34.5 mixed with demethylating agents, 5-Aza or decitabine (5-aza-2'-deoxycytidine), significantly prolonged the survival of athymic mice harboring intracranial human glioma xenografts over single agents alone. Interestingly, valproic acid also demethylated the nestin promoter and increased rQNestin34.5 replication (Okemoto et al., 2013a).

Copper in serum supports angiogenesis (Soncin et al., 1997; $\mathrm{Hu}, 1998$ ) and inhibits replication of wild-type HSV-1 (Shishkov et al., 1997). Copper chelators are currently being investigated as an antiangiogenic and antineoplastic agent for cancer patients (Lin et al., 2013). Yoo et al showed that physiologically relevant concentrations of copper $(1 \mathrm{mg} / \mathrm{L})$ inhibits oHSV rQNestin34.5 infection and replication, and copper chelation with ATN-224 reversed this copper-mediated oHSV inhibition (Yoo et al., 2012). In vivo, systemic administration of ATN224 augmented therapeutic efficacy of intratumoral rQNestin34.5 against intracranial GBM in athymic mice, which was associated with reduced vascular leakiness (Ktrans) and blood vessel density, suggesting anti-angiogenic effects by ATN-224 (Yoo et al., 2012). Importantly, systemic ATN-224 enhanced delivery and efficacy of systemically administered oHSV hrR3, as the combination significantly reduced tumor growth likely through ATN224-mediated increased stability of oHSV in serum (Yoo et al., 2012).

\section{"ARMED" VIRUSES EXPRESSING THERAPEUTIC TRANSGENES}

The presence of genes not essential for virus replication allows oHSV to accommodate relatively large sizes of exogenous DNA. oHSV engineered to carry therapeutic genes, so-called "armed oHSV," has been used to deliver and express therapeutic proteins in tumor cells in an attempt to enhance antitumor efficacy. The following sections will discuss recently described strategies in which "armed" oHSVs play a central role.

\section{Immunomodulating genes}

GBM promotes an immunosuppressive tumor microenvironment and the immune status of GBM patients is compromised (Rolle et al., 2012). oHSV can function as an "in situ vaccination" since oHSV-mediated tumor cell killing elicits anti-tumor immunity (Toda et al., 1999). Although stimulation of inflammation can lead to virus clearance before its amplification, strategies to enhance oHSV efficacy by expressing cytokines with immune activation properties appear promising.

Interleukin 12 is a prominent Th1 response inducer and known to promote anti-tumor cellular immunity. Expression of IL-12 in the context of oHSV enhances efficacy in the treatment of murine model of GBM (Hellums et al., 2005). Cheema et al. further demonstrated the utility of a murine IL12 armed oHSV, G47 $\Delta$-mIL12, in an immunocompetent murine GSC model (Cheema et al., 2013). G47 $\Delta$-mIL12 infects and replicates similarly to the unarmed oHSV counterpart in vitro, whereas it 
significantly enhances survival in syngeneic mice bearing intracerebral 005 GBMs in vivo (Cheema et al., 2013). Mechanistically, G47 $\Delta$-mIL12 evoked multifaceted beneficial responses including increased IFN- $\gamma$ release, anti-angiogenesis, and reduction of regulatory $\mathrm{T}$ cell infiltration to the tumor microenvironment. In vivo NK cell depletion and use of athymic mice revealed the requirement of T, but not NK cells for the efficacy of G47 $\Delta$-mIL12 (Cheema et al., 2013). Using the same HSV backbone, G47 $\Delta$ Flt3L was created to stimulate anti-tumor immunity through on site expression of soluble Flt3L, a cytokine capable of differentiating hematopoietic precursors into plasmacytoid and conventional dendritic cells (DCs) and mobilizing them from bone marrow (Barnard et al., 2012). In culture, high levels of Flt3L expressed by G47 $\Delta$-Flt3L did not affect viral replication or a cytotoxic effect on glioma cells. Direct inoculation of G47 $\Delta$ Flt3L into intracerebral CT2A gliomas in C57BL/6 mice resulted in detectable levels of Flt3L in the blood and was superior to parental G47 $\Delta$ in prolonging survival of animals (Barnard et al., 2012).

A study examining the safety and biodistribution of M032, a $\gamma 34.5$-deleted oHSV expressing human IL-12, in HSV-susceptible Aotus nonhuman primates was described very recently (Roth et al., 2014). A single intracerebral inoculation of $10^{6}$ or $10^{8} \mathrm{pfu}$ of M032 caused temporary slight body weight loss and mild to moderate inflammatory reactions in the brain, but was overall well tolerated. Viral DNA was detected in the brain and, at lower levels, in the spleen up to 91-day post inoculation (Roth et al., 2014).

\section{Anti-angiogenic genes}

Anti-angiogenic therapy targets neovasculature within the tumor microenvironment. A number of secreted proteins capable of inhibiting tumor-associated neo-angiogenesis have been identified, and used to arm oHSV to enhance overall efficacy through dual targeting of tumor cells and stromal vascular cells.

An oncolytic HSV ( $\gamma 34.5-$, ICP6-) carrying an endostatinangiostatin fusion gene (VAE) killed GSCs and the expression of endo-angio inhibited proliferation of human brain microvascular endothelial cells (HBMEC) compared to control oHSV (Zhu et al., 2011). In vivo, intratumoral injection of VAE extended survival of mice harboring intracerebral human GSC xenografts compared with control monotherapies, non-transgene encoding rHSV-1 or recombinant endostatin (Zhang et al., 2014).

Angiostatin is an antiangiogenic polypeptide, while interleukin-12 (IL-12) is an immunostimulatory cytokine with anti-angiogenic effects. A unique combination strategy using oHSVs expressing angiostatin (G47 $\Delta$-mAngio) and IL-12 $(\mathrm{G} 47 \Delta$-mIL12) was tested in orthotopic human GBM xenograft models (Zhang et al., 2013). Intratumoral injection of G47 $\Delta$ mAngio and G47 $\Delta$-mIL12 together in mice bearing intracranial U87 or GSCs-derived tumors significantly prolonged survival compared to each armed oHSV alone. This was associated with increased anti-angiogenesis and virus spread, as well as decreased macrophage infiltration (Zhang et al., 2013). These data support the use of oHSVs expressing multiple anti-angiogenic factors to improve efficacy in GBM.

\section{Prodrug-activating genes}

Prodrug-activating gene or suicide gene therapy uses the systemic delivery of an inactive prodrug coupled with tumor-specific expression of a drug-activating enzyme (the suicide gene), which converts the nontoxic prodrug to cytotoxic metabolites and causes tumor cell death (Duarte et al., 2012). Owning to limited off-site presence of the toxic substance, this strategy can negate serious adverse effects on normal tissues associated with systemic chemotherapy. oHSV armed with prodrug-activating genes not only exerts direct oncolytic killing but also produces bystander effects mediated by cytotoxic metabolites released from oHSVinfected cells.

MGH2, derived from MGH1 containing deletions of both copies of $\gamma 34.5$ and an inactivating insertion in UL39, carries two prodrug-activating transgenes: the cytochrome P450 2B1 (CYP2B1) and the secreted human intestinal carboxylesterase (shiCE) (Tyminski et al., 2005). CYP2B1 converts cyclophosphamide (CPA) into the active DNA-alkylating metabolite, phosphoramide mustard (PM), and shiCE activates irinotecan (CPT11) to the active topoisomerase 1 inhibitor, SN-38, in target cells. MGH2 exhibited anti-tumor activity against human glioma cells both in vitro and in vivo, which was enhanced by the addition of CPA and CPT11 (Tyminski et al., 2005). For clinical translation, Dr. Chiocca's group created MGH2.1 by removing the GFP expression cassette from MGH2, and performed toxicology and biodistribution studies (Kasai et al., 2013). After intracerebral injection in BALB/c mice, MGH2.1 DNA was detected in brains for up to 60 days, and expression of virally encoded genes was restricted to brain. Intracranial inoculation of MGH2.1 induced a small increase in serum IL-6 levels and did not cause lethality in HSV-permissive BALB/C mice at $10^{8}$ pfu without prodrugs and at $10^{6}$ with prodrugs. These safety and toxicology data justify a clinical trial of intratumoral injection of $\mathrm{MGH} 2.1$ with peripheral administration of CPA and/or CPT11 in patients with malignant gliomas.

\section{Pro-apoptotic genes}

Apoptotic pathways are often dysregulated in tumors, including GBM, and apoptosis induction with pro-apoptotic gene transfer has been investigated as an anti-GBM strategy (Abe et al., 2002; Lee et al., 2002). However, HSV, like other viruses, has inherent mechanisms that prevent host cells from undergoing premature apoptosis to sustain replication (Koyama and Miwa, 1997; Aubert and Blaho, 1999), and expressing exogenous apoptosis-inducing gene in the context of oHSV had not been explored till recently.

Tamura et al. created a recombinant G47 $\Delta$ oHSV that bears a transgene encoding a secretable TRAIL (tumor necrosis factor-related apoptosis-inducing ligand) (Tamura et al., 2013). This oHSV-TRAIL (G47 $\Delta$-TRAIL) showed enhanced cytotoxicity against TRAIL- or oHSV-resistant GBM cells compared to control oHSV without transgene. oHSV-TRAIL downregulated extracellular signal-regulated protein kinase (ERK)-mitogen-activated protein kinase (MAPK) and upregulated c-Jun N-terminal kinase (JNK) and p38-MAPK signaling, and induced resistant GBM cells to undergo apoptosis via activation of caspase-8, -9 , and -3 (Tamura et al., 2013). Furthermore, intratumoral inoculation of oHSV-TRAIL inhibited tumor invasiveness, and increased 
survival of SCID mice bearing oHSV-resistant intracerebral GBMs (Tamura et al., 2013), revealing the unique efficacy of G47 $\Delta$-TRAIL for treatment-refractory GBM.

\section{SUMMARY AND FUTURE DIRECTION}

oHSV-based treatment of GBM proceeds through a dynamic, complex process that involves virus infection, replication and spread, and activation of inflammatory and immune responses as well as modulation of tumor microenvironments. As we discussed, these variable aspects of oHSV therapy provide a variety of opportunities for interventions to improve overall efficacy and maintain safety. Furthermore, oHSV-mediated activation of cellular pathways such DNA repair response and PI3K/Akt pathway can be exploited by combinatorial approaches to enhance tumor cell death. In a simplified view, the process that takes place during
oHSV-based therapy can be divided into two phases (Figure 1). In phase 1, oHSV infects GBM cells, replicates, produces progeny and spreads within the tumor, resulting in oncolytic death of infected tumor cells. In subsequent phase 2, different strategies could be summoned that include activation of anti-tumor immunity and apoptosis induction in an attempt to eliminate residual unaffected part of the tumor with the goal to prevent relapse and enhance overall efficacy.

One major factor determining the success during phase 1 is delivery of therapeutic virus, which we did not discuss in detail in this article. Direct injection into tumor or brain surrounding the resection cavity is the only delivery method clinical trials have utilized. Although this approach enables oHSV to get into tumor bypassing the blood-brain barrier, there remains an issue how to deliver oHSV to tumor cells distant from the injection

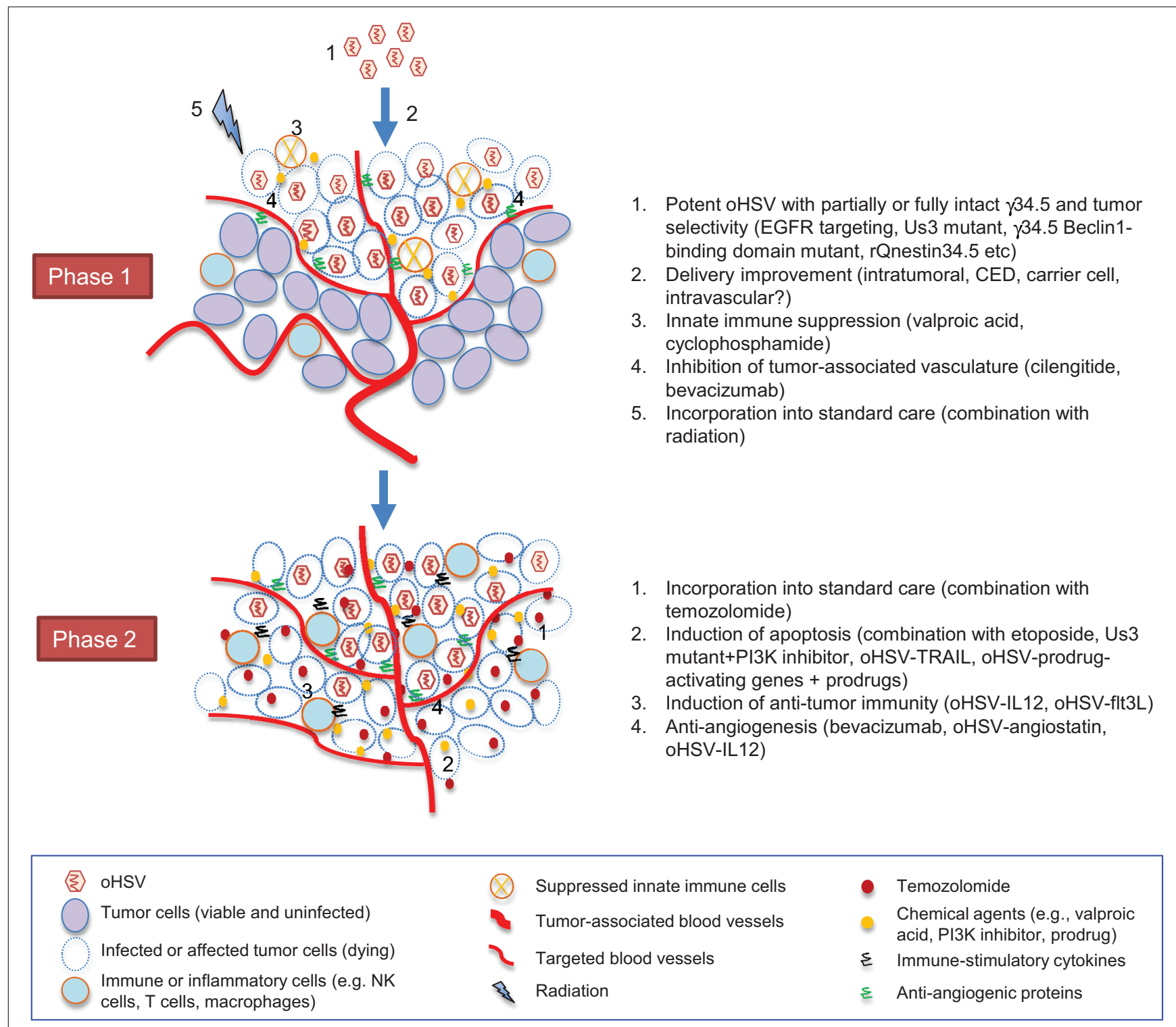

FIGURE 1 | Two-phasic process that oHSV-based strategies go through toward successful GBM tumor elimination. For each phase, representative interventional approaches that we discussed in the text are listed on the right. 
site. Convection-enhanced delivery (CED) (Debinski and Tatter, 2009) may enhance spatial distribution of intracerebrally injected oHSV (Hadjipanayis et al., 2008). Taking advantage of their capacity to home to tumors, neural or mesenchymal stem cells have been used as a vehicle for OV (Herrlinger et al., 2000; Ahmed et al., 2011; Duebgen et al., 2014). Virus-loaded stem cells can migrate and release virus at tumor sites distant from the injection. In addition, cell-carried viruses appear to be protected from clearance by cellular immunity. Intravascular delivery, either systemic intravenous or via carotid arterial, have been attempted for oHSV (Ikeda et al., 1999; Shikano et al., 2011) and other viruses (Liu et al., 2013b), and this approach may be worth revisiting with the aid of compounds such as CPA, valproic acid or copper chelator.

As summarized in Figure 1, we have now gained substantive knowledge about an array of strategies that could be useful to improve oHSV efficacy for GBM in the clinic. It is possible that achieving both efficient oHSV distribution within tumor (phase 1) and induction of extensive death of cells including oHSV-uninfected cells (phase 2) is necessary to obtain substantial efficacy. This could entail combined use of distinct and diverse approaches that include more potent but tumor-selective virus, current standard of care, anti-angiogenic agents, innate immune suppressors or molecular targeted agents, and on-site expression of therapeutic transgenes. The sequence and timing of each treatment may need careful consideration to optimize impacts. Because numerous combinations are now available, how to design feasible and mechanistically reasonable protocols aimed at efficient assessment of both safety and efficacy has become a significant challenge in clinical translation of novel oHSV strategies.

\section{ACKNOWLEDGMENTS}

The authors appreciate Dr. Samuel Rabkin for helpful suggestions on the article. This work was supported by grants from the NIH (R01NS032677 and R01CA160762).

\section{REFERENCES}

Abe, T., Wakimoto, H., Bookstein, R., Maneval, D. C., Chiocca, E. A., and Basilion, J. P. (2002). Intra-arterial delivery of p53-containing adenoviral vector into experimental brain tumors. Cancer Gene Ther. 9, 228-235. doi: 10.1038/sj.cgt. 7700437

Advani, S. J., Markert, J. M., Sood, R. F., Samuel, S., Gillespie, G. Y., Shao, M. Y., et al. (2011). Increased oncolytic efficacy for high-grade gliomas by optimal integration of ionizing radiation into the replicative cycle of HSV-1. Gene Ther. 18, 1098-1102. doi: 10.1038/gt.2011.61

Advani, S. J., Mezhir, J. J., Roizman, B., and Weichselbaum, R. R. (2006). ReVOLT: radiation-enhanced viral oncolytic therapy. Int. J. Radiat. Oncol. Biol. Phys. 66, 637-646. doi: 10.1016/j.ijrobp.2006.06.034

Advani, S. J., Sibley, G. S., Song, P. Y., Hallahan, D. E., Kataoka, Y., Roizman, B., et al. (1998). Enhancement of replication of genetically engineered herpes simplex viruses by ionizing radiation: a new paradigm for destruction of therapeutically intractable tumors. Gene Ther. 5, 160-165. doi: 10.1038/sj.gt.3300546

Aghi, M. K., Liu, T. C., Rabkin, S., and Martuza, R. L. (2009). Hypoxia enhances the replication of oncolytic herpes simplex virus. Mol. Ther. 17, 51-56. doi: $10.1038 / \mathrm{mt} .2008 .232$

Aghi, M., Rabkin, S., and Martuza, R. L. (2006). Effect of chemotherapy-induced DNA repair on oncolytic herpes simplex viral replication. J. Natl. Cancer Inst. 98, 38-50. doi: 10.1093/jnci/djj003

Aghi, M., Visted, T., Depinho, R. A., and Chiocca, E. A. (2008). Oncolytic herpes virus with defective ICP6 specifically replicates in quiescent cells with homozygous genetic mutations in p16. Oncogene 27, 4249-4254. doi: $10.1038 /$ onc. 2008.53
Ahmed, A. U., Thaci, B., Alexiades, N. G., Han, Y., Qian, S., Liu, F., et al. (2011). Neural stem cell-based cell carriers enhance therapeutic efficacy of an oncolytic adenovirus in an orthotopic mouse model of human glioblastoma. Mol. Ther. 19, 1714-1726. doi: 10.1038/mt.2011.100

Allen, C., Opyrchal, M., Aderca, I., Schroeder, M. A., Sarkaria, J. N., Domingo, E., et al. (2013). Oncolytic measles virus strains have significant antitumor activity against glioma stem cells. Gene Ther. 20, 444-449. doi: 10.1038/gt.2012.62

Alvarez-Breckenridge, C. A., Yu, J., Price, R., Wei, M., Wang, Y., Nowicki, M. O., et al. (2012a). The histone deacetylase inhibitor valproic acid lessens NK cell action against oncolytic virus-infected glioblastoma cells by inhibition of STAT5/T-BET signaling and generation of gamma interferon. J. Virol. 86, 4566-4577. doi: 10.1128/JVI.05545-11

Alvarez-Breckenridge, C. A., Yu, J., Price, R., Wojton, J., Pradarelli, J., Mao, H., et al. (2012b). NK cells impede glioblastoma virotherapy through NKp30 and NKp46 natural cytotoxicity receptors. Nat. Med. 18, 1827-1834. doi: 10.1038/nm.3013

Aubert, M., and Blaho, J. A. (1999). The herpes simplex virus type 1 regulatory protein ICP27 is required for the prevention of apoptosis in infected human cells. J. Virol. 73, 2803-2813.

Barnard, Z., Wakimoto, H., Zaupa, C., Patel, A. P., Klehm, J., Martuza, R. L., et al. (2012). Expression of FMS-like tyrosine kinase 3 ligand by oncolytic herpes simplex virus type I prolongs survival in mice bearing established syngeneic intracranial malignant glioma. Neurosurgery71, 741-748. discussion: 748. doi: 10.1227/NEU.0b013e318260fd73

Brooks, P. C., Montgomery, A. M., Rosenfeld, M., Reisfeld, R. A., Hu, T., Klier, G., et al. (1994). Integrin alpha v beta 3 antagonists promote tumor regression by inducing apoptosis of angiogenic blood vessels. Cell 79, 1157-1164. doi: 10.1016/0092-8674(94)90007-8

Brown, S. M., MacLean, A. R., McKie, E. A., and Harland, J. (1997). The herpes simplex virus virulence factor ICP34.5 and the cellular protein MyD116 complex with proliferating cell nuclear antigen through the 63-amino-acid domain conserved in ICP34.5, MyD116, and GADD34. J. Virol. 71, 9442-9449.

Chaurushiya, M. S., and Weitzman, M. D. (2009). Viral manipulation of DNA repair and cell cycle checkpoints. DNA Repair (Amst.). 8, 1166-1176. doi: 10.1016/j.dnarep.2009.04.016

Cheema, T. A., Kanai, R., Kim, G. W., Wakimoto, H., Passer, B., Rabkin, S. D., et al. (2011). Enhanced antitumor efficacy of low-dose Etoposide with oncolytic herpes simplex virus in human glioblastoma stem cell xenografts. Clin. Cancer Res. 17, 7383-7393. doi: 10.1158/1078-0432.CCR-11-1762

Cheema, T. A., Wakimoto, H., Fecci, P. E., Ning, J., Kuroda, T., Jeyaretna, D. S., et al. (2013). Multifaceted oncolytic virus therapy for glioblastoma in an immunocompetent cancer stem cell model. Proc. Natl. Acad. Sci. U.S.A. 110, 12006-12011. doi: 10.1073/pnas.1307935110

Chinot, O. L., Wick, W., Mason, W., Henriksson, R., Saran, F., Nishikawa, R., et al. (2014). Bevacizumab plus radiotherapy-temozolomide for newly diagnosed glioblastoma. N. Engl. J. Med. 370, 709-722. doi: 10.1056/NEJMoa1308345

Chiocca, E. A., Abbed, K. M., Tatter, S., Louis, D. N., Hochberg, F. H., Barker, F., et al. (2004). A phase I open-label, dose-escalation, multi-institutional trial of injection with an E1B-Attenuated adenovirus, ONYX-015, into the peritumoral region of recurrent malignant gliomas, in the adjuvant setting. Mol. Ther. 10, 958-966. doi: 10.1016/j.ymthe.2004.07.021

Das, S., and Marsden, P. A. (2013). Angiogenesis in glioblastoma. N. Engl. J. Med. 369, 1561-1563. doi: 10.1056/NEJMcibr1309402

Debinski, W., and Tatter, S. B. (2009). Convection-enhanced delivery for the treatment of brain tumors. Expert Rev. Neurother. 9, 1519-1527. doi: 10.1586/ern.09.99

Duarte, S., Carle, G., Faneca, H., de Lima, M. C., and Pierrefite-Carle, V. (2012). Suicide gene therapy in cancer: where do we stand now? Cancer Lett. 324, 160-170. doi: 10.1016/j.canlet.2012.05.023

Duebgen, M., Martinez-Quintanilla, J., Tamura, K., Hingtgen, S., Redjal, N., Wakimoto, H., et al. (2014). Stem cells loaded with multimechanistic oncolytic herpes simplex virus variants for brain tumor therapy. J. Natl. Cancer Inst. 106:dju090. doi: 10.1093/jnci/dju090

Ekstrand, A. J., Sugawa, N., James, C. D., and Collins, V. P. (1992). Amplified and rearranged epidermal growth factor receptor genes in human glioblastomas reveal deletions of sequences encoding portions of the $\mathrm{N}$ - and/or C-terminal tails. Proc. Natl. Acad. Sci. U.S.A. 89, 4309-4313. doi: 10.1073/pnas.89.10.4309

Eyler, C. E., and Rich, J. N. (2008). Survival of the fittest: cancer stem cells in therapeutic resistance and angiogenesis. J. Clin. Oncol. 26, 2839-2845. doi: 10.1200/JCO.2007.15.1829 
Forsyth, P., Roldan, G., George, D., Wallace, C., Palmer, C. A., Morris, D., et al. (2008). A phase I trial of intratumoral administration of reovirus in patients with histologically confirmed recurrent malignant gliomas. Mol. Ther. 16, 627-632. doi: 10.1038/sj.mt.6300403

Freeman, A. I., Zakay-Rones, Z., Gomori, J. M., Linetsky, E., Rasooly, L., Greenbaum, E., et al. (2006). Phase I/II trial of intravenous NDV-HUJ oncolytic virus in recurrent glioblastoma multiforme. Mol. Ther. 13, 221-228. doi: 10.1016/j.ymthe.2005.08.016

Friedlander, M., Brooks, P. C., Shaffer, R. W., Kincaid, C. M., Varner, J. A., and Cheresh, D. A. (1995). Definition of two angiogenic pathways by distinct alpha v integrins. Science 270, 1500-1502. doi: 10.1126/science.270.5241.1500

Friedman, G. K., Haas, M. C., Kelly, V. M., Markert, J. M., Gillespie, G. Y., and Cassady, K. A. (2012). Hypoxia moderates gamma(1)34.5-deleted herpes simplex virus oncolytic activity in human glioma xenoline primary cultures. Transl. Oncol. 5, 200-207. doi: 10.1593/tlo.12115

Friedman, G. K., Langford, C. P., Coleman, J. M., Cassady, K. A., Parker, J. N., Markert, J. M., et al. (2009). Engineered herpes simplex viruses efficiently infect and kill CD133+ human glioma xenograft cells that express CD111. J. Neurooncol. 95, 199-209. doi: 10.1007/s11060-009-9926-0

Fujii, K., Kurozumi, K., Ichikawa, T., Onishi, M., Shimazu, Y., Ishida, J., et al. (2013). The integrin inhibitor cilengitide enhances the anti-glioma efficacy of vasculostatin-expressing oncolytic virus. Cancer Gene Ther. 20, 437-444. doi: $10.1038 /$ cgt.2013.38

Fulci, G., Dmitrieva, N., Gianni, D., Fontana, E. J., Pan, X., Lu, Y., et al. (2007). Depletion of peripheral macrophages and brain microglia increases brain tumor titers of oncolytic viruses. Cancer Res. 67, 9398-9406. doi: 10.1158/00085472.CAN-07-1063

Gambini, E., Reisoli, E., Appolloni, I., Gatta, V., Campadelli-Fiume, G., Menotti, L., et al. (2012). Replication-competent herpes simplex virus retargeted to HER2 as therapy for high-grade glioma. Mol. Ther. 20, 994-1001. doi: $10.1038 / \mathrm{mt} .2012 .22$

Gerstner, E. R., and Batchelor, T. T. (2012). Antiangiogenic therapy for glioblastoma. Cancer J. 18, 45-50. doi: 10.1097/PPO.0b013e3182431c6f

Gilbert, M. R., Dignam, J. J., Armstrong, T. S., Wefel, J. S., Blumenthal, D. T., Vogelbaum, M. A., et al. (2014). A randomized trial of bevacizumab for newly diagnosed glioblastoma. N. Engl. J. Med. 370, 699-708. doi: 10.1056/NEJMoa1308573

Goetz, C., and Gromeier, M. (2010). Preparing an oncolytic poliovirus recombinant for clinical application against glioblastoma multiforme. Cytokine Growth Factor Rev. 21, 197-203. doi: 10.1016/j.cytogfr.2010.02.005

Goldstein, D. J., and Weller, S. K. (1988). Factor(s) present in herpes simplex virus type 1-infected cells can compensate for the loss of the large subunit of the viral ribonucleotide reductase: characterization of an ICP6 deletion mutant. Virology 166, 41-51. doi: 10.1016/0042-6822(88)90144-4

Gordon, Y. J., Gilden, D. M., and Becker, Y. (1983). HSV-1 thymidine kinase promotes virulence and latency in the mouse. Invest. Ophthalmol. Vis. Sci. 24, 599-602.

Grandi, P., Fernandez, J., Szentirmai, O., Carter, R., Gianni, D., Sena-Esteves, M., et al. (2010). Targeting HSV-1 virions for specific binding to epidermal growth factor receptor-vIII-bearing tumor cells. Cancer Gene Ther. 17, 655-663. doi: $10.1038 /$ cgt.2010.22

Gromeier, M., Lachmann, S., Rosenfeld, M. R., Gutin, P. H., and Wimmer, E. (2000). Intergeneric poliovirus recombinants for the treatment of malignant glioma. Proc. Natl. Acad. Sci. U.S.A. 97, 6803-6808. doi: 10.1073/pnas.97.12.6803

Hadjipanayis, C. G., and DeLuca, N. A. (2005). Inhibition of DNA repair by a herpes simplex virus vector enhances the radiosensitivity of human glioblastoma cells. Cancer Res. 65, 5310-5316. doi: 10.1158/0008-5472.CAN-04-3793

Hadjipanayis, C. G., Fellows-Mayle, W., and Deluca, N. A. (2008). Therapeutic efficacy of a herpes simplex virus with radiation or temozolomide for intracranial glioblastoma after convection-enhanced delivery. Mol. Ther. 16, 1783-1788. doi: $10.1038 / \mathrm{mt} .2008 .185$

Hardcastle, J., Kurozumi, K., Dmitrieva, N., Sayers, M. P., Ahmad, S., Waterman, P., et al. (2010). Enhanced antitumor efficacy of vasculostatin (Vstat120) expressing oncolytic HSV-1. Mol. Ther. 18, 285-294. doi: 10.1038/mt.2009.232

Harrow, S., Papanastassiou, V., Harland, J., Mabbs, R., Petty, R., Fraser, M., et al. (2004). HSV1716 injection into the brain adjacent to tumour following surgical resection of high-grade glioma: safety data and long-term survival. Gene Ther. 11, 1648-1658. doi: 10.1038/sj.gt.3302289
He, B., Gross, M., and Roizman, B. (1997). The gamma(1)34.5 protein of herpes simplex virus 1 complexes with protein phosphatase lalpha to dephosphorylate the alpha subunit of the eukaryotic translation initiation factor 2 and preclude the shutoff of protein synthesis by double-stranded RNA-activated protein kinase. Proc. Natl. Acad. Sci. U.S.A. 94, 843-848. doi: 10.1073/pnas.94.3.843

Hellums, E. K., Markert, J. M., Parker, J. N., He, B., Perbal, B., Roizman, B., et al. (2005). Increased efficacy of an interleukin-12-secreting herpes simplex virus in a syngeneic intracranial murine glioma model. Neuro Oncol. 7, 213-224. doi: $10.1215 /$ S1152851705000074

Herrero, Y. C. M., Cornelis, J. J., Herold-Mende, C., Rommelaere, J., Schlehofer, J. R., and Geletneky, K. (2004). Parvovirus H-1 infection of human glioma cells leads to complete viral replication and efficient cell killing. Int. J. Cancer 109, 76-84. doi: 10.1002/ijc.11626

Herrlinger, U., Woiciechowski, C., Sena-Esteves, M., Aboody, K. S., Jacobs, A. H., Rainov, N. G., et al. (2000). Neural precursor cells for delivery of replicationconditional HSV-1 vectors to intracerebral gliomas. Mol. Ther. 1, 347-357. doi: $10.1006 / \mathrm{mthe} .2000 .0046$

$\mathrm{Hu}, \mathrm{G}$. F. (1998). Copper stimulates proliferation of human endothelial cells under culture. J. Cell. Biochem. 69, 326-335.

Ikeda, K., Ichikawa, T., Wakimoto, H., Silver, J. S., Deisboeck, T. S., Finkelstein, D., et al. (1999). Oncolytic virus therapy of multiple tumors in the brain requires suppression of innate and elicited antiviral responses. Nat. Med. 5, 881-887. doi: $10.1038 / 11320$

Kambara, H., Okano, H., Chiocca, E. A., and Saeki, Y. (2005). An oncolytic HSV-1 mutant expressing ICP34.5 under control of a nestin promoter increases survival of animals even when symptomatic from a brain tumor. Cancer Res. 65, 2832-2839. doi: 10.1158/0008-5472.CAN-04-3227

Kanai, R., and Rabkin, S. D. (2013). Combinatorial strategies for oncolytic herpes simplex virus therapy of brain tumors. CNS Oncol. 2, 129-142. doi: $10.2217 / \mathrm{cns} .12 .42$

Kanai, R., Rabkin, S. D., Yip, S., Sgubin, D., Zaupa, C. M., Hirose, Y., et al. (2012a) Oncolytic virus-mediated manipulation of DNA damage responses: synergy with chemotherapy in killing glioblastoma stem cells. J. Natl. Cancer Inst. 104, 42-55. doi: 10.1093/jnci/djr509

Kanai, R., Wakimoto, H., Martuza, R. L., and Rabkin, S. D. (2011). A novel oncolytic herpes simplex virus that synergizes with phosphoinositide 3 kinase/Akt pathway inhibitors to target glioblastoma stem cells. Clin. Cancer Res. 17, 3686-3696. doi: 10.1158/1078-0432.CCR-10-3142

Kanai, R., Zaupa, C., Sgubin, D., Antoszczyk, S. J., Martuza, R. L., Wakimoto, H., et al. (2012b). Effect of gamma34.5 deletions on oncolytic herpes simplex virus activity in brain tumors. J. Virol. 86, 4420-4431. doi: 10.1128/JVI.00017-12

Kasai, K., Nakashima, H., Liu, F., Kerr, S., Wang, J., Phelps, M., et al. (2013). Toxicology and biodistribution studies for MGH2.1, an oncolytic virus that expresses two prodrug-activating genes, in combination with prodrugs. Mol. Ther. Nucleic Acids 2:e113. doi: 10.1038/mtna.2013.38

Kicielinski, K. P., Chiocca, E. A., Yu, J. S., Gill, G. M., Coffey, M., and Markert, J. M. (2014). Phase 1 clinical trial of intratumoral reovirus infusion for the treatment of recurrent malignant gliomas in adults. Mol. Ther. 22, 1056-1062. doi: $10.1038 / \mathrm{mt} .2014 .21$

Koyama, A. H., and Miwa, Y. (1997). Suppression of apoptotic DNA fragmentation in herpes simplex virus type 1-infected cells. J. Virol. 71, 2567-2571.

Kurozumi, K., Hardcastle, J., Thakur, R., Yang, M., Christoforidis, G., Fulci, G., et al. (2007). Effect of tumor microenvironment modulation on the efficacy of oncolytic virus therapy. J. Natl. Cancer Inst. 99, 1768-1781. doi: 10.1093/jnci/djm229

Lee, J., Hampl, M., Albert, P., and Fine, H. A. (2002). Antitumor activity and prolonged expression from a TRAIL-expressing adenoviral vector. Neoplasia 4, 312-323. doi: 10.1038/sj.neo.7900245

Li, Z., Bao, S., Wu, Q., Wang, H., Eyler, C., Sathornsumetee, S., et al. (2009). Hypoxia-inducible factors regulate tumorigenic capacity of glioma stem cells. Cancer Cell 15, 501-513. doi: 10.1016/j.ccr.2009.03.018

Lilley, C. E., Carson, C. T., Muotri, A. R., Gage, F. H., and Weitzman, M. D. (2005). DNA repair proteins affect the lifecycle of herpes simplex virus 1. Proc. Natl. Acad. Sci. U.S.A. 102, 5844-5849. doi: 10.1073/pnas.0501916102

Lin, J., Zahurak, M., Beer, T. M., Ryan, C. J., Wilding, G., Mathew, P., et al (2013). A non-comparative randomized phase II study of 2 doses of ATN224 , a copper/zinc superoxide dismutase inhibitor, in patients with biochemically recurrent hormone-naive prostate cancer. Urol. Oncol. 31, 581-588. doi: 10.1016/j.urolonc.2011.04.009 
Liu, S., Dai, M., You, L., and Zhao, Y. (2013a). Advance in herpes simplex viruses for cancer therapy. Sci. China Life Sci. 56, 298-305. doi: 10.1007/s11427-013-4466-4

Liu, T. C., Wakimoto, H., Martuza, R. L., and Rabkin, S. D. (2007). Herpes simplex virus Us3(-) mutant as oncolytic strategy and synergizes with phosphatidylinositol 3-kinase-Akt targeting molecular therapeutics. Clin. Cancer Res. 13, 5897-5902. doi: 10.1158/1078-0432.CCR-07-1013

Liu, Z., Zhao, X., Mao, H., Baxter, P. A., Huang, Y., Yu, L., et al. (2013b). Intravenous injection of oncolytic picornavirus SVV-001 prolongs animal survival in a panel of primary tumor-based orthotopic xenograft mouse models of pediatric glioma. Neuro Oncol. 15, 1173-1185. doi: 10.1093/neuonc/not065

MacLean, A. R., ul-Fareed, M., Robertson, L., Harland, J., and Brown, S. M. (1991). Herpes simplex virus type 1 deletion variants 1714 and 1716 pinpoint neurovirulence-related sequences in Glasgow strain 17+ between immediate early gene 1 and the 'a' sequence. J. Gen. Virol. 72(pt 3), 631-639. doi: 10.1099/0022-1317-72-3-631

Markert, J. M., Liechty, P. G., Wang, W., Gaston, S., Braz, E., Karrasch, M., et al. (2009). Phase Ib trial of mutant herpes simplex virus G207 inoculated preand post-tumor resection for recurrent GBM. Mol. Ther. 17, 199-207. doi: 10.1038/mt.2008.228

Markert, J. M., Medlock, M. D., Rabkin, S. D., Gillespie, G. Y., Todo, T., Hunter, W. D., et al. (2000). Conditionally replicating herpes simplex virus mutant, G207 for the treatment of malignant glioma: results of a phase I trial. Gene Ther. 7, 867-874. doi: 10.1038/sj.gt.3301205

Markert, J. M., Razdan, S. N., Kuo, H. C., Cantor, A., Knoll, A., Karrasch, M., et al. (2014). A phase i trial of oncolytic HSV-1, G207, given in combination with radiation for recurrent GBM demonstrates safety and radiographic responses. Mol. Ther. 22, 1048-1055. doi: 10.1038/mt.2014.22

Martuza, R. L., Malick, A., Markert, J. M., Ruffner, K. L., and Coen, D. M. (1991). Experimental therapy of human glioma by means of a genetically engineered virus mutant. Science 252, 854-856. doi: 10.1126/science.1851332

Marumoto, T., Tashiro, A., Friedmann-Morvinski, D., Scadeng, M., Soda, Y., Gage, F. H., et al. (2009). Development of a novel mouse glioma model using lentiviral vectors. Nat. Med. 15, 110-116. doi: 10.1038/nm.1863

McKie, E. A., Brown, S. M., MacLean, A. R., and Graham, D. I. (1998). Histopathological responses in the CNS following inoculation with a nonneurovirulent mutant (1716) of herpes simplex virus type 1 (HSV 1): relevance for gene and cancer therapy. Neuropathol. Appl. Neurobiol. 24, 367-372. doi: 10.1046/j.1365-2990.1998.00133.x

McKie, E. A., MacLean, A. R., Lewis, A. D., Cruickshank, G., Rampling, R., Barnett, S. C., et al. (1996). Selective in vitro replication of herpes simplex virus type 1 (HSV-1) ICP34.5 null mutants in primary human CNS tumoursevaluation of a potentially effective clinical therapy. Br. J. Cancer 74, 745-752. doi: 10.1038/bjc.1996.431

Menotti, L., Cerretani, A., Hengel, H., and Campadelli-Fiume, G. (2008). Construction of a fully retargeted herpes simplex virus 1 recombinant capable of entering cells solely via human epidermal growth factor receptor 2. J. Virol. 82, 10153-10161. doi: 10.1128/JVI.01133-08

Mineta, T., Rabkin, S. D., and Martuza, R. L. (1994). Treatment of malignant gliomas using ganciclovir-hypersensitive, ribonucleotide reductase-deficient herpes simplex viral mutant. Cancer Res. 54, 3963-3966.

Mineta, T., Rabkin, S. D., Yazaki, T., Hunter, W. D., and Martuza, R. L. (1995). Attenuated multi-mutated herpes simplex virus-1 for the treatment of malignant gliomas. Nat. Med. 1, 938-943. doi: 10.1038/nm0995-938

Murphy, A. M., and Rabkin, S. D. (2013). Current status of gene therapy for brain tumors. Transl. Res. 161, 339-354. doi: 10.1016/j.trsl.2012.11.003

Nduom, E. K., Hadjipanayis, C. G., and Van Meir, E. G. (2012). Glioblastoma cancer stem-like cells: implications for pathogenesis and treatment. Cancer J. 18, 100-106. doi: 10.1097/PPO.0b013e3182452e0d

Okemoto, K., Kasai, K., Wagner, B., Haseley, A., Meisen, H., Bolyard, C., et al. (2013a). DNA demethylating agents synergize with oncolytic HSV1 against malignant gliomas. Clin. Cancer Res. 19, 5952-5959. doi: 10.1158/10780432.CCR-12-3588

Okemoto, K., Wagner, B., Meisen, H., Haseley, A., Kaur, B., and Chiocca, E. A. (2013b). STAT3 activation promotes oncolytic HSV1 replication in glioma cells. PLoS ONE 8:e71932. doi: 10.1371/journal.pone.0071932

Orvedahl, A., Alexander, D., Talloczy, Z., Sun, Q., Wei, Y., Zhang, W., et al. (2007). HSV-1 ICP34.5 confers neurovirulence by targeting the Beclin 1 autophagy protein. Cell Host Microbe 1, 23-35. doi: 10.1016/j.chom.2006.12.001
Papanastassiou, V., Rampling, R., Fraser, M., Petty, R., Hadley, D., Nicoll, J., et al. (2002). The potential for efficacy of the modified (ICP 34.5(-)) herpes simplex virus HSV1716 following intratumoural injection into human malignant glioma: a proof of principle study. Gene Ther. 9, 398-406. doi: 10.1038/sj.gt.3301664

Parsons, D. W., Jones, S., Zhang, X., Lin, J. C., Leary, R. J., Angenendt, P., et al. (2008). An integrated genomic analysis of human glioblastoma multiforme. Science 321, 1807-1812. doi: 10.1126/science.1164382

Rampling, R., Cruickshank, G., Papanastassiou, V., Nicoll, J., Hadley, D., Brennan, D., et al. (2000). Toxicity evaluation of replication-competent herpes simplex virus (ICP 34.5 null mutant 1716) in patients with recurrent malignant glioma. Gene Ther. 7, 859-866. doi: 10.1038/sj.gt.3301184

Reisoli, E., Gambini, E., Appolloni, I., Gatta, V., Barilari, M., Menotti, L., et al. (2012). Efficacy of HER2 retargeted herpes simplex virus as therapy for highgrade glioma in immunocompetent mice. Cancer Gene Ther. 19, 788-795. doi: $10.1038 / \mathrm{cgt} .2012 .62$

Rolle, C. E., Sengupta, S., and Lesniak, M. S. (2012). Mechanisms of immune evasion by gliomas. Adv. Exp. Med. Biol. 746, 53-76. doi: 10.1007/978-1-46143146-6_5

Roth, J. C., Cassady, K. A., Cody, J. J., Parker, J. N., Price, K. H., Coleman, J. M., et al. (2014). Evaluation of the safety and biodistribution of M032, an attenuated herpes simplex virus type 1 expressing hIL-12, after intracerebral administration to aotus nonhuman primates. Hum. Gene Ther. Clin. Dev. 25, 16-27. doi: 10.1089/humc.2013.201

Russell, S. J., Peng, K. W., and Bell, J. C. (2012). Oncolytic virotherapy. Nat. Biotechnol. 30, 658-670. doi: 10.1038/nbt.2287

Seidel, S., Garvalov, B. K., Wirta, V., von Stechow, L., Schanzer, A., Meletis, K., et al. (2010). A hypoxic niche regulates glioblastoma stem cells through hypoxia inducible factor 2 alpha. Brain 133, 983-995. doi: 10.1093/brain/awq042

Senzer, N. N., Kaufman, H. L., Amatruda, T., Nemunaitis, M., Reid, T., Daniels, G., et al. (2009). Phase II clinical trial of a granulocyte-macrophage colony-stimulating factor-encoding, second-generation oncolytic herpesvirus in patients with unresectable metastatic melanoma. J. Clin. Oncol. 27, 5763-5771. doi: 10.1200/JCO.2009.24.3675

Sgubin, D., Wakimoto, H., Kanai, R., Rabkin, S. D., and Martuza, R. L. (2012). Oncolytic herpes simplex virus counteracts the hypoxia-induced modulation of glioblastoma stem-like cells. Stem Cells Transl. Med. 1, 322-332. doi: 10.5966/sctm.2011-0035

Shen, Y., and Nemunaitis, J. (2006). Herpes simplex virus 1 (HSV-1) for cancer treatment. Cancer Gene Ther. 13, 975-992. doi: 10.1038/sj.cgt.7700946

Shikano, T., Kasuya, H., Sahin, T. T., Nomura, N., Kanzaki, A., Misawa, M., et al. (2011). High therapeutic potential for systemic delivery of a liposomeconjugated herpes simplex virus. Curr. Cancer Drug Targets 11, 111-122. doi: 10.2174/156800911793743673

Shishkov, S., Varadinova, T., Panteva, M., and Bontchev, P. (1997). Effect of complexes of zinc, cobalt and copper with D-Aminosugars on the replication of herpes simplex virus type 1 (HSV-1). Met. Based Drugs 4, 35-38. doi: 10.1155/MBD.1997.35

Soncin, F., Guitton, J. D., Cartwright, T., and Badet, J. (1997). Interaction of human angiogenin with copper modulates angiogenin binding to endothelial cells. Biochem. Biophys. Res. Commun. 236, 604-610. doi: 10.1006/bbrc.1997.7018

Stupp, R., Mason, W. P., van den Bent, M. J., Weller, M., Fisher, B., Taphoorn, M. J., et al. (2005). Radiotherapy plus concomitant and adjuvant temozolomide for glioblastoma. N. Engl. J. Med. 352, 987-996. doi: 10.1056/NEJMoa043330

Sugawa, N., Ekstrand, A. J., James, C. D., and Collins, V. P. (1990). Identical splicing of aberrant epidermal growth factor receptor transcripts from amplified rearranged genes in human glioblastomas. Proc. Natl. Acad. Sci. U.S.A. 87, 8602-8606. doi: 10.1073/pnas.87.21.8602

Tamura, K., Wakimoto, H., Agarwal, A. S., Rabkin, S. D., Bhere, D., Martuza, R. L., et al. (2013). Multimechanistic tumor targeted oncolytic virus overcomes resistance in brain tumors. Mol. Ther. 21, 68-77. doi: 10.1038/mt.2012.175

Taylor, T. J., and Knipe, D. M. (2004). Proteomics of herpes simplex virus replication compartments: association of cellular DNA replication, repair, recombination, and chromatin remodeling proteins with ICP8. J. Virol. 78, 5856-5866. doi: 10.1128/JVI.78.11.5856-5866.2004

Toda, M., Rabkin, S. D., Kojima, H., and Martuza, R. L. (1999). Herpes simplex virus as an in situ cancer vaccine for the induction of specific anti-tumor immunity. Hum. Gene Ther. 10, 385-393. doi: 10.1089/10430349950018832 
Todo, T., Martuza, R. L., Rabkin, S. D., and Johnson, P. A. (2001). Oncolytic herpes simplex virus vector with enhanced MHC class I presentation and tumor cell killing. Proc. Natl. Acad. Sci. U.S.A. 98, 6396-6401. doi: 10.1073/pnas.1011 36398

Tyminski, E., Leroy, S., Terada, K., Finkelstein, D. M., Hyatt, J. L., Danks, M. K., et al. (2005). Brain tumor oncolysis with replication-conditional herpes simplex virus type 1 expressing the prodrug-activating genes, CYP2B1 and secreted human intestinal carboxylesterase, in combination with cyclophosphamide and irinotecan. Cancer Res. 65, 6850-6857. doi: 10.1158/0008-5472.CAN-05-0154

Uchida, H., Marzulli, M., Nakano, K., Goins, W. F., Chan, J., Hong, C. S., et al. (2013). Effective treatment of an orthotopic xenograft model of human glioblastoma using an EGFR-retargeted oncolytic herpes simplex virus. Mol. Ther. 21, 561-569. doi: 10.1038/mt.2012.211

Wakimoto, H., Fulci, G., Tyminski, E., and Chiocca, E. A. (2004). Altered expression of antiviral cytokine mRNAs associated with cyclophosphamide's enhancement of viral oncolysis. Gene Ther. 11, 214-223. doi: 10.1038/sj.gt.3302143

Wakimoto, H., Kesari, S., Farrell, C. J., Curry, W. T., Jr., Zaupa, C., Aghi, M., et al. (2009). Human glioblastoma-derived cancer stem cells: establishment of invasive glioma models and treatment with oncolytic herpes simplex virus vectors. Cancer Res. 69, 3472-3481. doi: 10.1158/0008-5472.CAN-08-3886

Wen, P. Y., and Kesari, S. (2008). Malignant gliomas in adults. N. Engl. J. Med. 359, 492-507. doi: 10.1056/NEJMra0708126

Wollmann, G., Ozduman, K., and van den Pol, A. N. (2012). Oncolytic virus therapy for glioblastoma multiforme: concepts and candidates. Cancer J. 18, 69-81. doi: 10.1097/PPO.0b013e31824671c9

Yoo, J. Y., Pradarelli, J., Haseley, A., Wojton, J., Kaka, A., Bratasz, A., et al. (2012). Copper chelation enhances antitumor efficacy and systemic delivery of oncolytic HSV. Clin. Cancer Res. 18, 4931-4941. doi: 10.1158/1078-0432.CCR12-0697

Zhang, G., Jin, G., Nie, X., Mi, R., Zhu, G., Jia, W., et al. (2014). Enhanced antitumor efficacy of an oncolytic herpes simplex virus expressing an endostatin-angiostatin fusion gene in human glioblastoma stem cell xenografts. PLoS ONE 9:e95872. doi: 10.1371/journal.pone.0095872

Zhang, W., Fulci, G., Buhrman, J. S., Stemmer-Rachamimov, A. O., Chen, J. W., Wojtkiewicz, G. R., et al. (2012). Bevacizumab with angiostatin-armed oHSV increases antiangiogenesis and decreases bevacizumab-induced invasion in U87 glioma. Mol. Ther. 20, 37-45. doi: 10.1038/mt.2011.187

Zhang, W., Fulci, G., Wakimoto, H., Cheema, T. A., Buhrman, J. S., Jeyaretna, D. S., et al. (2013). Combination of oncolytic herpes simplex viruses armed with angiostatin and IL-12 enhances antitumor efficacy in human glioblastoma models. Neoplasia 15, 591-599. doi: 10.1593/neo.13158

Zhu, G., Su, W., Jin, G., Xu, F., Hao, S., Guan, F., et al. (2011). Glioma stem cells targeted by oncolytic virus carrying endostatin-angiostatin fusion gene and the expression of its exogenous gene in vitro. Brain Res. 1390, 59-69. doi: 10.1016/j.brainres.2011.03.050

Conflict of Interest Statement: The authors declare that the research was conducted in the absence of any commercial or financial relationships that could be construed as a potential conflict of interest.

Received: 30 April 2014; accepted: 03 June 2014; published online: 20 June 2014.

Citation: Ning J and Wakimoto H (2014) Oncolytic herpes simplex virus-based strategies: toward a breakthrough in glioblastoma therapy. Front. Microbiol. 5:303. doi: 10.3389/fmicb.2014.00303

This article was submitted to Virology, a section of the journal Frontiers in Microbiology.

Copyright (C) 2014 Ning and Wakimoto. This is an open-access article distributed under the terms of the Creative Commons Attribution License (CC BY). The use, distribution or reproduction in other forums is permitted, provided the original author(s) or licensor are credited and that the original publication in this journal is cited, in accordance with accepted academic practice. No use, distribution or reproduction is permitted which does not comply with these terms. 